\title{
Penerapan Model Movement Problem Based Learning Soccer Like Games
}

\author{
*Nurul Fauzi ${ }^{1}$, Luqmanul Hakim Lubay ${ }^{1}$ \\ ${ }^{1}$ Program Studi Pendidikan Guru Sekolah Dasar Pendidikan Jasmani, \\ Fakultas Pendidikan Olahraga dan Kesehatan, Universitas Pendidikan Indonesia
}

\begin{abstract}
Abstrak
Penelitian ini bertujuan untuk meneliti keterampilan bermain siswa melalui penerapan model movement problem based learning dalam soccer like games. Metode penelitian yang digunakan melalui metode Penelitian Tindakan Kelas, Tempat penelitian di Sekolah Dasar Negri Tagog dengan objek penelitian siswa kelas IV berjumlah 25 orang. Proses penelitian dibagi menjadi II siklus, setiap siklus terdiri dari 2 tindakan. Setiap tindakan menggunakan berbagai tugas gerak yang dikemas dalam bentuk permainan. Data dikumpulkan dengan menggunakan instrumen GPAI. Kemudian semua data yang terkumpul dianalisis menggunakan teknik persentase. Nilai rata-rata keseluruhan data awal adalah 59\% dan siklus I tindakan I adalah $66 \%$, siklus I tindakan II adalah $68 \%$, siklus II tindakan I adalah $72 \%$, dan siklus II tindakan II adalah 76\%. Dari rata-rata aspek keterampilan bermain berdasarkan hasil analisis data, diperoleh kesimpulan bahwa melalui penerapan model movement problem based learning dapat meningkatkan keterampilan bermain siswa dalam pembelajaran soccer like games. Sebagai saran dari hasil penelitian, dalam pemberian materi pembelajaran soccer like games, hendaknya diberikan berbagai tugas gerak yang dikemas dalam bentuk permainan.
\end{abstract}

Kata kunci : Model Movement Problem Based Learning, Soccer Like

Games

\footnotetext{
* Nurul Fauzi adalah lulusan Program Studi PGSD Penjas, Departemen Pendidikan Olahraga, Fakultas
} Pendidikan Olahraga dan Kesehatan, Universitas Pendidikan Indonesia. 


\title{
Implementation Of Movement Problem Based Learning Model On Soccer-Like Games
}

\begin{abstract}
s
This research aim is to investigate the acquisition of children games skills through the implementation of movement problem based learning model on soccer-like games. The method to be employed in this study is A Classroom Action Research, consisting of two cycles in which each cycle comprise of two treatment actions. This research is conducted in SDN (Public Primary School) Tagog, involving a group of 25 students of the fourth grade as the research subjects. All students are deliberately involved in the leraning process containing various gradually increasing steps in terms of difficulty, as the soccer-like games procedure demanded it. The data then collected with using GPAI as the main instrument combined with field notes and documentation. The obtained data then be analyzed with percentage technique, eliciting the followings: the average of initial data was 59\%, the average of cycle 1 of action 1 was $66 \%$, the average of cycle 1 of action 2 was $68 \%$, the average of cycle 2 action 1 was $72 \%$, and the average of cycle 2 action 2 was $76 \%$. It is concluded that the implementation of movement problem based learning model in soccer like games activities has improved the game skill of children..
\end{abstract}

Keyword : Movement Problem Based Learning model, Soccer Like Games.

\section{PENDAHULUAN}

Pendidikan jasmani merupakan suatu proses pembelajaran yang menggunakan aktivitas fisik dalam pembelajaran utamanya. Maka dari itu proses pembelajaran pendidikan jasmani, pertumbuhan dan perkembangan intelektual, sosial dan emosional anak sebagian besar terjadi melalui aktivitas gerak atau motorik yang dilakukan oleh anak. Tujuan pendidikan jasmani yaitu bukan hanya sekedar aktivitas jasmani itu sendiri, tetapi untuk mengembangkan potensi keterampilan siswa melalui aktivitas jasmani lewat gerak atau permainan dan olahraga (Mahendra, 2009). 
Pendidikan jasmani dalam Standar Kompetensi dan Kompetensi Dasar disebutkan bahwa ruang lingkup materi pembelajaran meliputi permainan dan olahraga, tradisional, permainan, eksplorasi gerak, keterampilan lokomotor non-lokomotor,dan manipulatif, atletik, kasti, rounders, kippers, sepakbola, bolabasket, bolavoli, tenis meja, tenis lapangan, bulu tangkis, dan beladiri, serta aktivitas lainnya.

Seiring perkembangan zaman, banyak sekali jenis olahraga yang dapat dipelajari dari pendidikan jasmani khususnya di Sekolah Dasar, salah satunya adalah jenis olahraga permainan sepakbola. Permainan sepakbola untuk pembelajaran pendidikan jasmani di Sekolah Dasar terlalu menyeluruh, dengan seiring perkembangan zaman agar siswa belajar dengan lebih mudah maka pembelajaran permainan sepakbola di Sekolah Dasar menggunakan Soccer Like Games (Bahagia, 2010).

Pembelajaran permainan sepakbola juga tidak hanya mengembangkan keterampilan bermainnya, melainkan melalui intervensi dan rekayasa guru dalam pelaksanaan pembelajaran. Guru harus mampu mengembangkan seluruh potensi-potensi kognitif dan afektif yang dimiliki siswa untuk ditumbuh kembangkan secara optimal, selain itu mengembangkan potensi yang dimiliki siswa. Guru juga harus memperhatikan sarana dan prasarana seperti lapangan demi terlaksananya pembelajaran, namun tidak dipungkiri penguasaan prinsip-prinsip dasar kelengkapan sarana dan prasarana permainan sepakbola belum menjamin tercapainya tujuan pembelajaran pendidikan jasmani yang diharapkan.Dalam pembelajaran pendidikan jasmani masih dipengaruhi oleh masalah yang berasal dari diri 
siswa dan penggunaan model-model pembelajaran yang digunakan oleh guru pendidikan jasmani.

Berdasarkan observasi awal di kelas IV SDN Tagog, dalam pembelajaran permainan sepakbola masih banyak siswa yang kurang memahami dan tidak bisa melakukan keterampilan dalam pembelajaran permainan sepakbola, karena siswa kurang paham dengan apa yang telah dijelaskan oleh guru pendidikan jasmani. Hal itu disebabkan karena kurangnya antusias dan semangat siswa dalam mengikuti pembelajaran pendidikan jasmani, sehingga siswa merasa bosan dan kurang nyaman dengan proses pembelajaran pendidikan jasmani. Selain itu model-model pembelajaran yang digunakan oleh guru pendidikan jasmani cenderung tidak bervariatif, maka dari itu peneliti melihat adanya permasalahan penggunaan modelmodel pembelajaran yang digunakan oleh guru pendidikan jasmani. Melalui penerapan model movement problem based learning, diharapkan dapat memecahkan masalah pembelajaran pendidikan jasmani. Hal ini disebabkan karena melalui model movementproblem based learning, siswa didorong untuk melakukan proses pembelajaran pendidikan jasmani secara berkelompok serta menyelesaikan masalahnya untuk tujuan bersama.

Salah satu pemilihan model pembelajaran yang digunakan oleh guru pendidikan jasmani adalah model movement problem based learning agar siswa dapat memecahkan masalahnya sendiri. Seperti yang dipaparkan Hmelo-Silver, 2004; Serafino \& Cicchelli, 2005, (dalam Paul Eggen dan Kauchak, 2012, hlm 307. Diterjemahkan oleh Wahono, 2012) adalah "seperangkat model mengajar yang menggunakan masalah sebagai fokus 
untuk mengembangkan keterampilan pemecahan masalah, materi dan penguatan diri". Selain mengembangkan keterampilan pemecahan masalah, materi dan penguatan diri, disesuaikan juga dengan jenis materi, karakteristik siswa, serta situasi siswa atau kondisi dimana proses pembelajaran pendidikan jasmani akan berlangsung. Oleh karena itu, penggunaan model movement problem base learning disesuaikan dengan konsep aktivitas pembelajaran permainan sepakbola pada siswa Sekolah Dasar yakni siswa mencari dan menemukan dasar masalah belajar pada pembelajaran permainan sepakbola kemudian di arahkan untuk berpikir dan memecahkan berdasarkan pengalamannya sendiri.

Berdasarkan uraian di atas, perlu dilakukan penelitian tentang penerapan model movement problem based learning dalam melakukan keterampilan bermain dengan aspek keputusan yang diambil, melaksanakan keterampilan, dan memberi dukungan dalam pembelajaran soccer like games. Hasil penelitian ini diharapkan dapat memberikan masukan bagi guru dalam mengembangkan dan meningkatkan kualitas pembelajaran soccer like games di Sekolah Dasar Negri Tagog.

\section{METODE PENELITIAN}

Metode yang digunakan menggunakan penelitian tindakan kelas (PTK). Subjek penelitian dalam PTK ini adalah siswa kelas IV SDN Tagog yang berjumlah 25 siswa dengan 13 siswa laki-laki dan 12 siswi perempuan, rata-rata tinggi badan sisa $130 \mathrm{~cm}$, berat badan $26 \mathrm{~kg}$, dan usia 11 tahun. Peserta didik di sekolah ini berasal dari latar belakang keluarga yang berbeda-beda, orang tua mereka berasal dari profesi yang berbeda-beda 
pula, ada yang berprofesi sebagai pedagang, karyawan, petani dan lainlain.

\section{Pengumpulan Data}

Data penelitian dikumpulkan dan disusun melalui teknik pengumpulan data yang meliputi: sumber data, jenis data, teknik pengumpulan data dan teknik analisis data.

1. Sumber Data: Yang menjadi data dalam penelitian ini adalah siswa kelas IV SDN Tagog.

2. Jenis Data: Jenis data yang didapat adalah data kuantitatif yang terdiri dari hasil belajar, rencana pembelajaran, dan hasil observasi terhadap pelaksanaan pembelajaran.

3. Teknik Pengumpulan Data: Data hasil belajar diambil dengan memberikan tes kepada siswa, data tentang situasi pembelajaran pada saat dilaksanakan tindakan diambil dengan menggunakan lembar observasi

Penulis mengunakan lembar observasi yang diberikan kepada observer, yaitu lembar observasi siswa.Lembar observasi ini berisikan penilaian aspek psikomotor, yaitu keterampilan passing.

\section{HASIL DAN PEMBAHASAN}

Berdasarkan data pengamatan di atas, hasil belajar siswa dalam mengikuti pembelajaran pendidikan jasmani khususnya dalam meningkatkan keterampilan bermain dalam soccer like games sangat memuaskan karena memperoleh hasil rata-rata persentasenya $76 \%$ sehingga dapat dikatagorikan sangat memuaskan, karena nilai yang diperoleh sudah melebihi dari target minimal peneliti yaitu 75\%. Berdasarkan hasil tersebut, hasil belajar siswa SDN Tagog sangat memuaskan. 


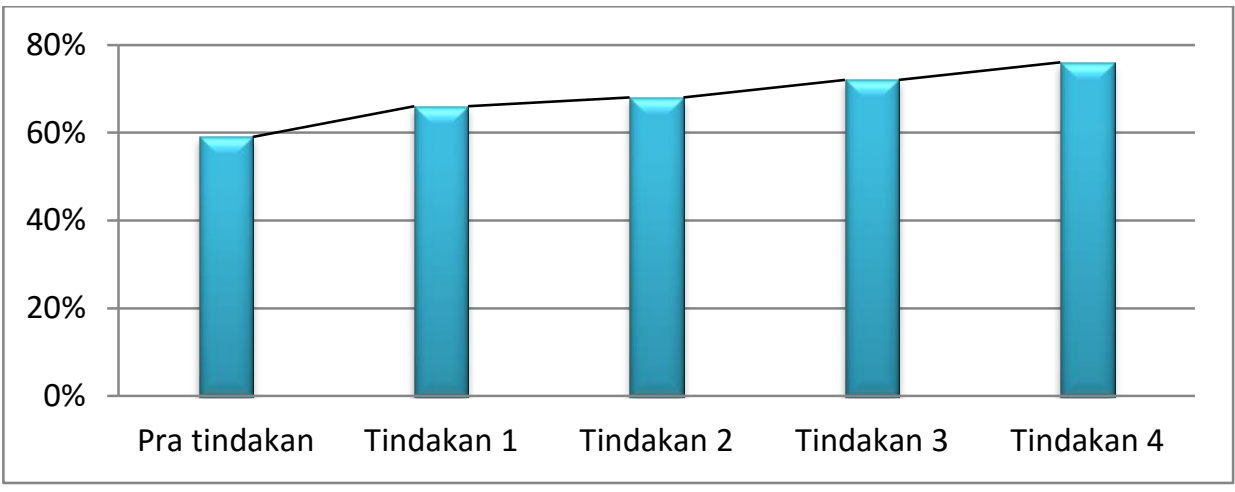

\section{Grafik 1 \\ Grafik Perolehan Nilai Keseluruhan Keterampilan Bermain dari Setiap Tindakan}

Pada grafik diatas, dapat dilihat di siklus I tindakan I memperoleh persentase $66 \%$ yang mengalami peningkatan dari observasi awal yang memperoleh 59\% mengalami peningkatan sebesar 7\%, selanjutnya siklus I tindakan II memperoleh persentase $68 \%$ mengalami peningkatan $2 \%$ dari siklus I tindakan I yang mendapatkan persentase 66\%. Kemudian dari siklus II tindakan I mendapatkan persentase $72 \%$ mengalami peningkatan dari siklus I tindakan II sebesar 4\% dan meningkat di siklus II tindakan II dengan hasil $76 \%$.

\section{KESIMPULAN}

Dari hasil penelitian yang telah dilaksanakan oleh peneliti dari mulai observasi awal sampai dengan tindakan terakhir, yaitu siklus II tindakan II, nilai presentase data awal adalah 59\%, siklus I tindakan I adalah 66\%, siklus I tindakan II adalah 68\%, siklus II tindakan I adalah 72\%, dan siklus II tindakan II adalah 76\%. Berdasarkan hasil penelitian mulai dari observasi awal sampai dengan siklus ke dua tindakan ke dua, dapat 
diketahui bahwa hasil belajar siswa dalam pembelajaran aktivitas soccer like games kelas IV SDN Tagog meningkat dari nilai presentase keseluruhan 59\% menjadi $76 \%$, peneliti menyimpulkan bahwa dengan diterapkannyamodel pembelajaran movement problem based learning hasil belajarsiswa dalam pembelajaran aktivitas soccer like games siswa kelas IV SDN Tagog meningkat. 


\section{DAFTAR PUSTAKA}

Abduljabar, B. dan Darajat, J. (2012).Aplikasi Statistika dalam Penjas.Bandung: UPI.

Bahagia, Y. (2010). Permainan Invasi. Bandung: FPOK-UPI

Eggen,P. \& Kauchak,D. (2012). Strategi dan Model Pembelajaran. Boston: Person. Dalam terjemahan Bahasa Indonesia Satrio Wahono

Mahendra, A. (2009). Asas dan Falsafah Pendidikan Jasmani.Bandung : FPOK UPI.

Purwanto, N (2014). Prinsip-prinsip Dan Teknik Evaluasi Pengajaran. PT Remaja Rosdakarya: Bandung. 